\title{
A possible selves intervention to enhance school involvement
}

\author{
Daphna Oyserman, Kathy Terry and Deborah Bybee
}

\begin{abstract}
We developed a 9-week after-school, small group, activities-based intervention focused on enhancing youth's abilities to imagine themselves as successful adults and connecting these future imagines to current school involvement. We describe and evaluate this programme comparing three cohorts of urban African American middle school students ( $n=62$ experimental, $n=146$ control), controlling for sex and previous school involvement. By the end of the school year, intervention youth reported more bonding to school, concern about doing well in school, "balanced" possible selves, plausible strategies to attain these possible selves, better school attendance, and for boys, less trouble at school.
\end{abstract}

(C) 2002 The Association for Professionals in Services for Adolescents. Published by Elsevier Science Ltd. All rights reserved

\section{Introduction}

The transition from school to work marks entrance into adulthood; imagining the adult one could become is part of this process (Cantor et al., 1987). Adolescents can think hypothetically, allowing them to visualize possible futures (Csiksezentmihalyi and Larson, 1984; Damon and Hart, 1986; Higgins, 1996; Strauman and Higgins, 1987; Harter 1990a, b) but schools typically do not structure or support connecting present school involvement with adult futures. Youth must creatively imagine this connection and link current behaviour to future adult selves on their own (Otto, 1991) but this is difficult, especially for poor (Bernstein, 1991; Myers et al., 1992; Petersen et al., 1993) and minority youth, especially African American youth, given historical racism and exclusion of African Americans from educational and occupational opportunities (Neighbors et al., 1989; Flaskerud and Li-Tze, 1992; Myers et al., 1992; Adeimpe, 1994).

Lacking a clear plan of how current involvement in school facilitates obtaining desired adult future selves, African American youth from low-income families are at high risk of school failure and subsequent unemployment (or marginal employment, see Gibbs and Hines, 1989; Kamii, 1990; Bowman, 1992; Solorzano, 1992; Price et al., 1993; Nettles and Perna, 1997). The current paper includes three parts. We first outline the link between possible selves, African American racial identity and school involvement. Second, we describe an intervention focused on helping youths develop clear and detailed possible selves, and third we assess the impact of this intervention on school involvement, focusing on the implications of this for our understanding of how possible selves may be fostered in social contexts.

\section{Definition and consequences}

Possible selves are the future-oriented component of self-concept. Youth construct possible selves by synthesizing what they know about their traits and abilities and what they know of the skills needed to become various future selves (Cantor et al., 1987; Anderson, 1991;

Reprint requests and correspondence should be addressed to: Daphna Oyserman, Institute for Social Research, University of Michigan, 426 Thompson, Ann Arbor, MI 48109-1248, U.S.A. (E-mail: daphna.@umich.edu) 
Crane, 1991; Curry et al., 1994). Possible selves are hypothetical images (the self one would like to attain, the self one would like to avoid) critical for motivating action (Strauman and Higgins, 1987; Higgins, 1996; Moretti and Higgins, 1990; Oyserman and Markus, 1990a). Youth with school-focused possible selves are at reduced risk of involvement in delinquent activities (Oyserman and Markus, 1990a, b; Oyserman and Saltz, 1993), attain better school outcomes (Oyserman et al., 1995; Oyserman and Harrison, 1998), and feel more connected to school (Oyserman, 1993; Oyserman and Harrison, 1998).

\section{Relationship with racial identity and school involvement}

There is some empirical support for the assumption that academic possible selves are rooted in part in racial identity. At least three elements of racial identity-awareness of racism, positive sense of in-group connectedness, and embedded achievement - have been shown to buffer low-income African American middle school youth from loss of academic self-efficacy (Oyserman et al., 2001a, b), disengagement from school (Oyserman et al., 2001a, b) and reduced persistence on academic tasks (Oyserman et al., 1995). Fordham's (1988) qualitative analysis suggests that some low-income African American youth feel that they must choose between personal achievement goals and identifying as "Black". because they do not see school success and blackness as congruent. However, research by Ford (1992) suggests that African American youth sometimes do perceive school achievement as self-defining.

\section{Limitations of past research and current focus}

Low-income African American youth may find it difficult to create positive and believable possible selves focused on school as a pathway to adulthood unless these possible selves are fostered in a social context that creates local norms highlighting the relevance of academic achievement for being African American. However, relevant research (e.g. Fordham, 1988; Ford, 1992; Oyserman and Saltz, 1993; Oyserman et al., 1995) is mostly correlational and necessarily leaves unanswered the question of how to translate findings about correlations between possible selves, school involvement and racial identity into a framework for change. To address this issue, we developed a brief intervention, outlined below, designed to engage low-income African American youth in developing clearly articulated possible selves that linked current school involvement with adult futures. We assumed that if we could help youth articulate achievement-oriented possible selves in a positive peer-based social context that implicitly framed academic achievement as part of African American racial identity, we should be able to bolster not only youth's possible selves but also their sense of connection to school and involvement in school more generally.

\section{An intervention to change possible selves}

Based on the evidence that content of possible selves can motivate school involvement and persistence, we sought to develop an intervention that could promote development of detailed, plausible, academically focused possible selves that could help youth feel connected and involved with school. Our goal was that the intervention would highlight and elicit the relevance of school to attaining one's possible selves. We focused on a small-group-based intervention with low-income African American youth in their last year of middle school for a number of reasons, including developmental stage and risk issues. In terms of developmental phase, we viewed early adolescence and the transition from middle school 
to high school as ideal times to study possible selves in action. Youth of this age are cognitively able to conceptualize possible selves and are on the brink of the important transition to high school, so they are likely to be beginning to speculate about what the future will hold for them. In terms of risk, as outlined above, risk of failing to develop academically focused possible selves is particularly high for low-income youth. Youth who are both low income and African American are likely to be doubly at risk compared with white middle or higher income youth. These youth face particular difficulties in the adolescent transition due to the combined risk of fewer minority role models for success and more neighbourhood exposure to unemployment, poverty, crime and other social risk factors. Therefore, we focused on African American youth living in a high-poverty inner city context as described in the sample.

We used a small-group, active learning paradigm with a series of small group activities within which youth gain a sense of their own vision for the future and learn to develop strategies to help attain this vision; parents and community members join in developing youth's skills. Figure 1 presents a conceptual model of the change process. To emphasize the connection between current action and future goals, we called the program "School-toJobs". We utilized a social cognitive approach, utilizing basic social psychological theory and research on the nature of information processing and motivation (Carver and Scheier, 1981; Bandura, 1986; Dweck and Leggett, 1988; Elliott and Dweck, 1988; Baumeister et al., 1994; Heatherton and Nichols, 1994; Mischel, 1996). This research suggests that structured activities occurring in everyday settings can have great impact on who we think we are and what is possible for us to achieve, because subtle contextual shifts can powerfully change the sense made of daily experiences. The meaning made of everyday experience in turn fuels motivation.

Specifically, our goal was to develop a sequence of activities and tasks that would provide youth with experiences of creating and detailing more explicit academic possible selves (e.g. Higgins, 1996) and then give them practice in the skills needed to engage in and put effort into school (e.g. Finn and Rock, 1997). We reasoned that helping youth define explicit

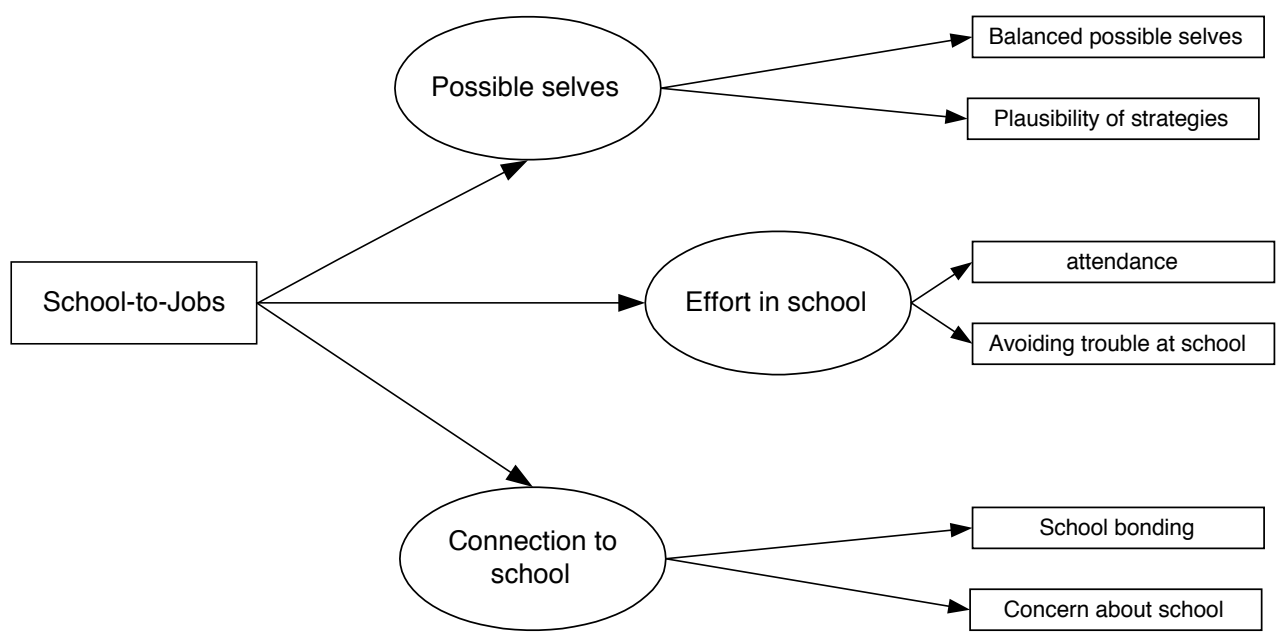

Figure 1. Model of hypothesized effects of the School-to-Jobs intervention. 
possible selves and link them to effort would result in better outcomes, and that these improved outcomes themselves would subsequently influence possible selves and effort over time, producing a positive cycle of change. Activities were designed to create well-explicated possible selves with clear, comprehensive, plausible strategies to achieve a positive academic self in the short run and to connect that self to one's desired adult selves in the longer run.

To minimize disruption while maintaining connection to school, we provided the program after-school. We sought to include parents and community members in order to anchor youth in an adult worldview, provide opportunities to practice skills needed to obtain support from adults, and allow youth to see that their emerging possible selves were supported by parents and community members. We decided that the best way to do this was to bring in adults as tools for youth rather than as teachers or authority figures. Our initial research suggested that many youth did not see a connection between the present and adulthood, which seemed far away. Therefore, we strove first to allow youth space to articulate their adult images, time to draw out a timeline to the future and a chance to see for themselves the connection between present and future which would create a group belief that the present influences one's future chances. By doing this, we reasoned, we could develop group interest in figuring out how to succeed in school, and work on strategies and skills for dealing with everyday problems in school. Only after these group tasks were completed would it make sense to bring parents and community members into the group. Otherwise, adults would simply be "tuned out" as not relevant. Therefore, the first seven sessions involved only youth and the last two sessions (sessions eight and nine) included parents and community members. In the Methods section, we provide a thumbnail sketch of each session to clarify both what activities took place and their connection with possible selves; the full manual is available from the first author.

\section{Study Methods}

\section{Sample}

We worked with an overwhelmingly African American inner city middle school where over $90 \%$ of students were eligible for free or reduced lunch, and students lived in neighbourhoods with over $40 \%$ of families living in poverty (according to 1990 Census information). The sample derives from 3 years of data collection (1995-96, 1997-98 and 1998-99). Data from the few non-African American youth attending the school in 1995-96 were dropped from analyses and none were involved in the intervention.

The total possible $N$ for analyses was 208, which represents the total number of African American students with baseline (Fall) and year-end (Spring) data $(n=80$ in 1995-96, $n=54$ in 1997-98, and $n=74$ in 1998-99). Over the years of data collection, length of the in-class period used for data collection varied from year to year, so we were not able to administer all of the questions to all three cohorts, resulting in varying sample sizes for analyses between 148 (90 girls and 58 boys) and 208 (113 girls and 95 boys). This latter sample of 208 includes 62 youth who received the intervention and 146 who did not. For specific analyses, sample sizes vary slightly due to missing data.

\section{Procedure}

Youth were not reimbursed for attendance to the School-to-Jobs programme but we made every effort to create activities youth would enjoy. In fact, participation in the after school 
sessions was excellent, with over $80 \%$ of students enrolled in the School-to-Jobs programme participating on average. Parent sessions ran only in the first year due to budget constraints. The sample does not include students who enrolled in the school for only part of the school year because they were missing either baseline or end of year data and so could not be included in these analyses.

Initial development and testing of the School-to-Jobs programme occurred during the 1995-96 school year, and subsequent testing occurred in the 1997-98 and 1998-99 school years. The intervention manual was refined as a result our experiences in 1995-96. Oyserman and Terry led or co-led the 1995-96 intervention sessions. Undergraduates supervised by these authors led subsequent cohorts. The undergraduates were enrolled in an experiential psychology course and received course credit for the semester spent training to lead groups and leading groups.

The programme took place weekly after school during a 9-week period each year so that it was not a salient part of the school day, reducing the possibility of a self-fulfilling prophecy effect whereby teachers expect different behaviour from programme youth. While we informed teachers about the after school program in a regularly scheduled teachers' meeting, teachers were not provided information as to who would be involved and did not have any particular involvement with the programme since it occurred after school. The after school sessions ran for $90 \mathrm{~min}$. Parent sessions took place at a nearby university campus and ran for $3 \mathrm{~h}$ each.

We described the programme in letters sent home to parents; only youth whose parents agreed to their participation were included in the intervention. The flyer described the programme as containing after school activities designed to help youth develop specific strategies for reaching their goals as adults. Programme and control youth did not differ significantly at baseline on grades $\left(M_{x}=6 \cdot 43 ; M_{c}=6 \cdot 12 ; t(d f=189)=-1 \cdot 62, p=0 \cdot 11\right)$.

To ascertain effects, we compared intervention and non-intervention youth at baseline (fall) and at year-end (spring). We obtained pre-intervention and end of year assessment measures through in-class completion of questionnaires during a single class throughout the eighth grade. We maintained identifying information on a separate list so that we could link fall and spring responses; otherwise, questionnaires were anonymous. To assess the impact of the intervention, we used analysis of covariance (ANCOVA), controlling for gender, cohort (initial vs. subsequent years) and previous level of the dependent variable in question. As is the case for all urban schools in poor neighbourhoods, the student body was transient, with a third of the youth present at the beginning of the year no longer present by the end of the year, with new students taking their place. In addition, a citywide drop in school funding resulted in loss of school buses after the first year and further reduced attendance.

\section{Thumbnail sketch of School-to-Jobs programme sessions}

(1) Creating a group (Goal: create a positive sense of membership and set the stage for school involvement and adult possible selves). Facilitators and participants share expectations and concerns about programme content, and participants develop programme rules. Activities include introducing one another in terms of skills and abilities to succeed in the eighth-grade, human knot and other activities which build the idea that group members have positive attributes related to school achievement and that others also want to do well in school.

(2) Adult images (Goal: to create a concrete experience of imagining adulthood). Participants choose among pictures portraying adults in the domains of work, family, lifestyle, 
community service, health and hobbies. Each participant in turn describes his or her images. Pictures are of racial-ethnic minority adults of various ages. Making choices and hearing others' choices provides an opportunity for thinking about the future and the domains involved.

(3) Time lines (Goal: to concretize the connection between present and future and to normalize failures and setbacks as part of progress to the future). Participants draw personal time lines from the present as far into the future as they can. Facilitators define forks in the road (choices that have consequences) and roadblocks (obstacles placed by others and situations-lack of financial resources, racial and/or sexual discrimination). Participants draw at least one of each as part of their timeline. Discussion connects current activities to future visions, and youth give and receive group feedback on sequences and ways to go around obstacles.

(4) Possible selves and strategies boards (Goal: to concretize the connection between current behaviour, next year, and adult attainments). Using poster board and coloured stickers, participants map out their next year and adult possible selves and the strategies they are using now or could use to work on these. Next, participants map out the school-related possible selves represented in the class and the strategies used to work on these. Participants using particular strategies have a chance to explain what they are doing and guide participants not currently using these strategies through obstacles preventing their use.

(5) Solving everyday problems I (Goal: to provide participants with concrete experience breaking down everyday school problems into more manageable parts). Working together reinforces components of racial identity (they all care about succeeding in school and others can be resources). In prior sessions, solo activities were the springboard to group discussion. The next sessions use a group activity as springboard because participants are confident enough in one another to work together in small groups. Participants solve logic problems together, developing a strategy of writing down the known to solve for the unknown. Using this success as a springboard, each group develops strategies for handling a set of schoolfocused problems (doing poorly in math a class, a big history assignment) by first listing the questions they must ask themselves or get information about prior to deciding on a course of action. The session ends with full group discussion of questions raised and decisions made.

(6) Solving everyday problems II (Goal: to reinforce participants' ability to make schoolrelated plans for the future and the need to reach out to adults to accomplish this). Using the same small group format as in the previous session, participants develop a list of requirements for high school graduation and prerequisites/skills needed for entry into college and other training, then work as a large group to find out about the actual requirements for local educational institutions. This is connected back to the adult visions, time lines, and strategy board sessions - helping youth see the process by which they can attain the adult selves they have imagined and deal with possible obstacles or forks in the road.

(7) Wrapping up, moving forward (Goal: to organize experiences so far and set the stage for bringing parents to the group). Participants "walk through" the programme by discussing what they did in each session, what they learned in each and what they liked and disliked about the programme so far. Parent or other important adult's involvement is discussed with a focus on how these adults from the youth's own racial-ethnic community can help youth on their pathways to adulthood. Youth explore the similarities and differences they see between their own experiences and those they imagine their parents had.

(8) Building an alliance and developing communication skills (Goal: to allow youth and parents to state their concerns for the student in the coming year, see limitations of current 
communication skills in handling these concerns, and practice another model in a structured setting). First, parents and youth introduce one another and youth lead a review of previous sessions. Then parents and youth separate to discuss what concerns each have about the transition to high school. These concerns form the basis for discussion of how to communicate with one another on important topics. Facilitators role-play parent and youth suggestions and then formulate a model of communication including active listening and "taking the floor". Parents pair off with their own youth to try out being an active listener and taking the floor. Each has a chance to experience each role, so each raises and reacts to a point of concern. Afterwards participants talk about the experience and commit to practice this skill before the next session. This section focuses on racial identity by highlighting connections between parents and youth, the importance of school, and difficulties encountered along the way.

(9) Jobs, careers and informational interviewing (Goal: to identify gaps in knowledge about how schooling links to careers and provide youth with skills to obtain this information). First, parents describe how they got their current job (or strategies they have tried to get jobs in the past if not currently employed) and youth describe how to find out about jobs and careers. Facilitators highlight parent and youth frustration about connecting qualifications and experiences to desired careers and jobs, thus introducing the concept of informational interviewing. Parents and youth practice informational interviewing and then utilize this skill to do informational interviews with community members who join the group at this point. Then participants discuss ways that they can use informational interviewing at a number of junctures in the future. Youth talk about barriers to contacting people in the community who have jobs that seem of interest to them. Community members discuss ways to make contacts, responding to specific concerns raised by youth and giving youth a chance to role-play these strategies. This session focuses on racial identity components by highlighting role models from youth's racial-ethnic community.

\section{Measures}

Connection to school. School bonding We assessed bonding with a 3-item 5-point Likert scale anchored at $1=$ strongly disagree, $5=$ strongly agree. The items, "I feel I really belong at school" "I try hard in school" "Schoolwork is very important" $(\alpha=0.67)$, are from Cernkovich and Giordano's (1992) school bonding scale.

Concern about school. We assessed concern with a 6-item 5-point scale anchored at $1=$ never, $5=$ all the time. Example items were (1) I feel worried or concerned when I have to read and understand something for a class assignment. (2) I feel worried or concerned when I have to write an essay $(\alpha=0 \cdot 72)$, revised from Fleming and Courtney (1984) academic subscale of the Feelings of Inadequacy Scale.

\section{Possible selves}

"Balanced" academic possible selves. We assessed balance with open-ended probes following a previously developed script (Oyserman and Markus, 1990a, b; Oyserman and Saltz, 1993). Students were asked to generate four or more possible selves in response to each of two probes: "Next year, I expect to be..."; "Next year I want to avoid being...." Content analyses suggested that most self-descriptions focused on school (example expectations are "next year I will be getting good grades" and "I will be in high school").

We content coded balance by reading the open-ended expected and feared possible selves and counting the number of times youth described school-focused goals in terms of a positive 
expectation "balanced" by a related school-focused concern described as a feared self. We coded the number of these "balanced" pairs of expected feared possible selves showing two sides of academic self-visions (e.g. Next year I expect to be in high school, next year I want to avoid still being in the eighth grade). Previous research (Oyserman and Markus, 1990a, b) suggests that this method captures the motivational focus needed to engage in school rather than other activities. To obtain inter-rater reliability, we coded the first third of the interviews separately and ascertained that we had at least $90 \%$ agreement in our coding of balanced pairs.

Plausible strategies (for attaining school-oriented possible selves). After writing in their possible selves, students marked those possible selves they were currently working on and wrote what they were doing to try to attain (or avoid negative) possible selves. Examples of strategies include "doing my homework", "not talking in class", and "set my alarm clock". We coded the plausibility of strategies youth generated to attain (or avoid) the school-focused possible selves on a 0 to 4 scale where, $0=$ no strategies, $1=1$ strategy, $2=$ at least two strategies, $3=$ two or more strategies that connect together, $4=$ detailed, concrete, reasonable roadmap, that takes into account both one's own and others' actions or perspectives.

\section{Effort in school}

Avoiding getting in trouble. School disciplinary action was not uniformly stored in student files so we used a single item self-report question "How often are you sent out of the classroom or to the office?" With a 5-point response scale: $1=$ more than once a week, $4=$ once a month or so, $5=$ in trouble less than once a month.

Attending. School attendance records were uneven so that a self-report measure was again used with a single item "How often are you absent from school?" $(1=$ more than once a week, $2=$ once a week or so, $3=$ once every few weeks, $4=$ once a month or so, $5=$ less than once a month).

\section{Results}

\section{Analysis plan}

To test the hypothesized impact of the School to Jobs intervention on possible selves and important school outcomes, we compared youth who attended the intervention with those who did not on post-test measures administered in the final weeks of the school year. Although (as described in the next section) there was no evidence of pre-existing differences between youth in the two conditions, we used gender, cohort and pre-test scores on the same measures, administered in the fall, as covariates in analyses of covariance to enhance power and increase the precision of the comparisons; means presented in the figures below are covariate-adjusted. We examined one-tailed contrasts for directional intervention effects attributable to the intervention.

\section{Baseline}

At baseline, before the intervention, intervention and control youth did not differ significantly on school bonding $\left(M_{x}=4 \cdot 49\right.$ vs. $\left.M_{c}=4 \cdot 33, t(\mathrm{df}=146)=-1 \cdot 21, p=0 \cdot 23\right)$, concern about school $\left(M_{x}=1.97\right.$ vs. $\left.M_{c}=2 \cdot 20, t(d f=193)=1 \cdot 81, p=0 \cdot 07\right)$, number of "balanced" possible selves $\left(M_{x}=0.57\right.$ vs. $\left.M_{c}=0.61, \quad t(d f=203)=0.32, \quad p=0.75\right)$, 
plausibility of their strategies to attain these possible selves $\left(M_{x}=1 \cdot 69\right.$ vs. $M_{c}=1 \cdot 67$, $t(\mathrm{df}=203)=1 \cdot 67, p=0.89)$, the frequency at which they got in trouble at school $\left(M_{x}=4.43\right.$ vs. $\left.M_{c}=4.57, t(d f=184)=0.81, p=0.42\right)$ or their school attendance $\left(M_{x}=4.04\right.$ vs. $\left.M_{c}=4 \cdot 12, t(d f=188)=0 \cdot 42, p=0 \cdot 67\right)$.

\section{Post}

At the end of the school year, as is detailed below, intervention and control youth differed on each of the measures of interest in our analyses of covariance, controlling for sex, cohort, and baseline level of each measure as outlined above. We tested each dependent variable for the possibility of a gender by intervention 2-way interaction effect, and we found a gender interaction effect only for our measure of avoiding trouble in school. Because sample size varied for each analysis, we list the number of control and intervention youth in each figure.

Effort in school. As can be seen in Figure 2, by the end of the school year, intervention youth reported a greater sense of bonding to school $F(1,139)=3 \cdot 53, p=0 \cdot 03, d=0 \cdot 36$ and more concern about doing well in school $F(1,186)=3 \cdot 40, p=0 \cdot 04, d=0 \cdot 25$.
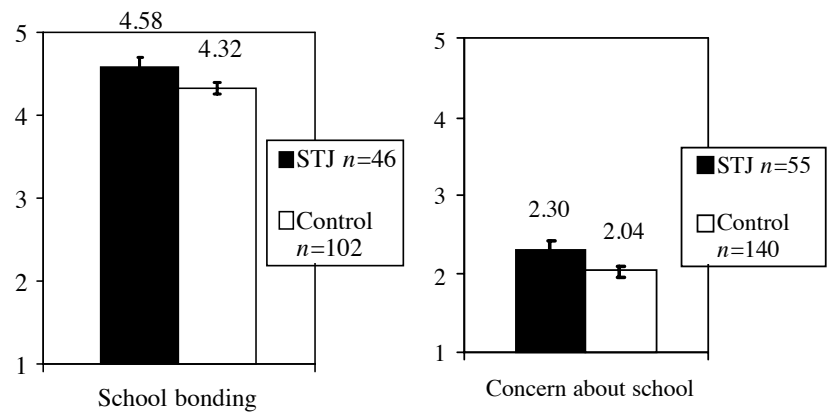

Figure 2. ANCOVA analyses of impact of School-to-Jobs intervention on school bonding (controlling cohort, sex, prior bonding) and concern about school (controlling cohort, sex, prior and concern).

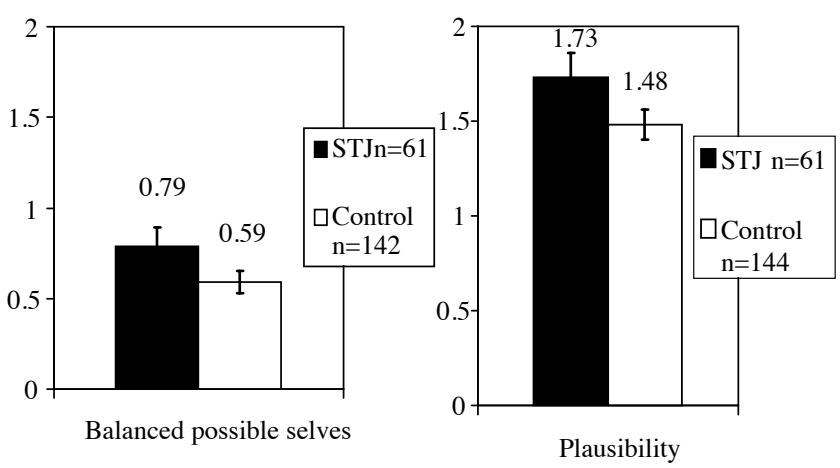

Figure 3. ANCOVA analyses of impact of School-to-Jobs intervention on balanced school-related possible selves (controlling cohort, sex, and prior balance) and plausibility of strategies to attain these possible selves (controlling cohort, sex, and prior plausibility). 
Possible selves. As can be seen in Figure 3, by the end of the school year, intervention youth reported more "balanced" possible selves, $F(1,196)=3 \cdot 10, p=0 \cdot 04, d=0.28$ and, at trend level, more plausible strategies to attain these possible selves, $F(1,196)=2 \cdot 50, p=0 \cdot 06$, $d=0 \cdot 25$.

Self-report of school behaviours. As can be seen in Figure 4, by the end of the school year, intervention youth reported that they less frequently got into trouble at school, $F(1,177)$ $=1.94, p=0.08, d=0.22$ and this effect was modified by a gender-by-intervention two-way interaction, $F(1,177)=5 \cdot 03,2$-tailed $p=0.03$. The intervention helped boys reduce the frequency they were sent out of the classroom or to the office for misbehaviour $(d=0.33$ for

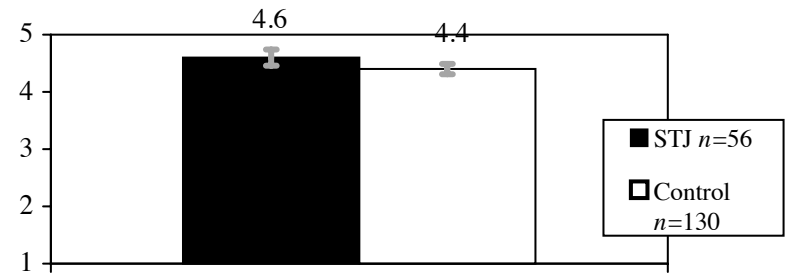

Avoiding Trouble at School

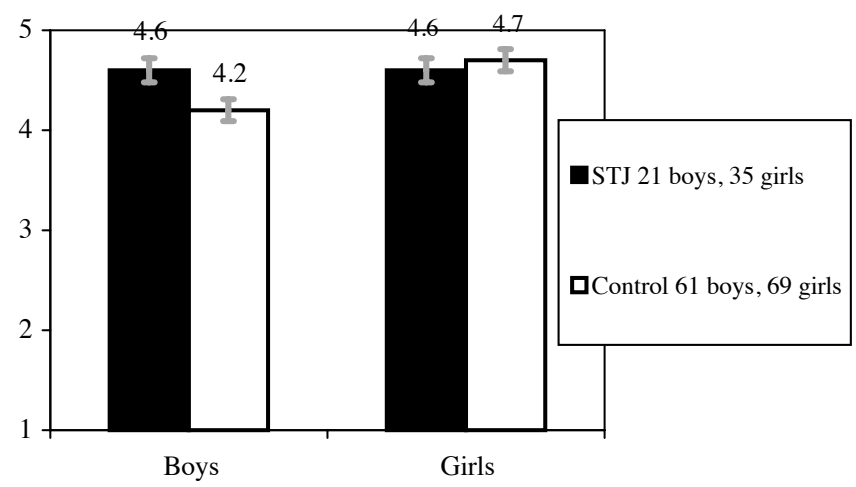

Figure 4. ANCOVA analyses of impact of School-to-Jobs intervention on trouble at school (main effect and interaction with gender) controlling for cohort and prior level of trouble at school).

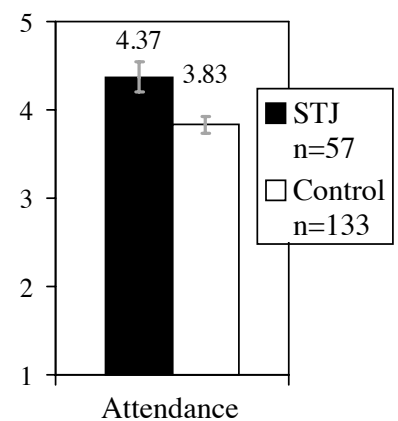

Figure 5. ANCOVA analyses of impact of School-to-Jobs intervention on school attendance controlling for cohort, sex, and prior attendance. 
boys). Sample size was adequate to support examination of this interaction (intervention group boys $n=21$, girls $n=35$; control group boys $n=61$, girls $n=69$ ). Similarly, as can be seen in Figure 5 , by the end of the school year, intervention youth were higher in school attendance, $F(1,181)=7 \cdot 77, p=0 \cdot 003, d=0.45$.

\section{Discussion}

Social and developmental psychologists have linked elements of self-concept with school success. Students with academically oriented possible selves report better grades (Oyserman and Harrison, 1998). Students who feel more scholastically able and who think others find them competent in school have higher self-esteem (Harter, 1996). In spite of this positive relationship between self-worth and academic success, youth often fear disapproval of their peers if they succeed academically (Juvonen, 1996), and this may be especially true for African American youth (McWhorter, 2000). Fears of social exclusion can motivate youth to avoid engaging in school (Dweck, 1996). A key question for applied researchers becomes how to facilitate emergence of academic focus in youth, especially youth who are at risk of dis-engaging from school and academic pursuits.

Equally important for applied researchers is the question of malleability of self-concept. Can structured intervention shift youth's self-concept to focus more on school and academics? Research on the relationship between self-concept and school attainment, even when longitudinal, has been primarily correlational, comparing outcomes for individuals differing in self-concept content rather than attempting to manipulate self-concept directly. In the current study, we attempted to change an aspect of self-concept, possible selves, directly to see if change in possible selves would also improve school engagement. We developed an intervention focused on possible selves and asked if such an intervention can influence possible selves and engagement in school. We found that a short group-based intervention can effectively bolster academic possible selves and improve engagement.

We believe that a number of factors are jointly responsible for the intervention's success. First, we focused on changing possible selves in the youth's everyday social environment. This meant that youth did not have to transfer insight gained in one context to another-since they learned new ways of thinking about themselves in the context of school and with their school peers. Second, we focused on changing possible selves within a racially congruent context and through activities designed to focus on elements of racial identity - positive sense of connection, academic achievement as part of racial identity, and awareness of racism. This meant that youth did not have to figure out how to integrate their newly articulated possible selves with racial identity on their own, defusing the question of whether school success is "black" or if it is acceptable to their peers - since their peers were involved in the same process. Third, we focused on changing possible selves by giving youth the opportunity to see the connections between present and future at their own pace, through activities shared with a group rather than "insight" based discussion. This allowed youth to see their own competencies and build positive interaction strategies with peers, parents and other adults rather than focus on problems, deficits and negatives. Fourth, we focused on changing possible selves in a mixed sex context-because our observation of youth interaction in the eighth grade suggested that African American youth are not gender segregated and that both boys and girls were assertive in creating space for themselves. 
Our intervention focused on helping youth (1) articulate specific academically oriented possible selves, (2) connect possible selves for the coming year to specific strategies to attain these selves, (3) connect these short-term possible selves and strategies to adult possible selves, and (4) develop skills to effectively interact with others in order to attain these possible selves. Our results show that it had positive effects for school engagement, school behaviours and possible selves.

Limitations of the study are due to its sample size, focus on a single school, analyses of effects over the course of a single school year, and reliance on brief self-report measures of variables of interest. As is often true in field research, our real-world laboratory was not static. Each year the amount of time that we had available for data collection changed to fit the school's changing length of class time (which ranged from 40 to $60 \mathrm{~min}$ ). In addition, congruent with the high level of poverty and other risk factors in urban inner city schools, a third of the student body was transient over the course of a single school year. Further, our sample size, pre-post design and lack of more longitudinal data did not allow us to study the process by which our intervention influenced possible selves. We speculate that the social context of the intervention was key but do not have process data as to the impact of youth's perceptions of peer norms on their own possible selves.

Future research is needed to provide larger samples, add longitudinal perspective and multiple informants as well as quantitative assessment of the intervention process. Our study, even with its limitations, does provide some important insights. Some of the limitations of this project also are advantages, increasing the ecological validity of our approach (e.g. our focus on high-risk youth attending a poor, mostly African American and relatively transient school). Other strengths are operationalization of possible selves and use of multiple cohorts with multiple trainers. We are currently attempting to replicate the intervention, code process information and obtain teacher reports as well as behavioural diary data to supplement the more global self-report information on behaviour and attitude change we were able to obtain in the current study. Future research, with more schools and following youth over longer periods of time will be needed to document the long-term effects of the intervention. However, the current study does provide evidence that self-concept can be effectively shaped in middle school with a structured intervention, and the findings underscore the importance of identity for school engagement.

\section{Acknowledgements}

We thank everyone involved in the intervention, Detroit Initiative student trainers from the University of Michigan, middle school students and parents, and community members. Partial funding came from a W. T. Grant Faculty Scholars award and the Michigan Prevention Research Center, NIMH Grant \#P50MH38330 (Richard Price and Amiram Vinokur, PIs) to Oyserman. I would also like to thank the Center for Advanced Studies in the Behavioral Sciences, Stanford, for its gracious support during the writing of this manuscript and Tami Hart Johnson for creating the data figures.

\section{References}

Adebimpe, V. R. (1994). Race, racism and epidemiological surveys. Hospital and Community Psychiatry, $45,27-31$. 
Anderson, L. P. (1991). Acculturative stress: a theory of relevance to Black Americans. Clinical Psychology Review, 11, 685-702.

Bandura, A. (1986). From thought to action: mechanisms of personal agency. New Zealand Journal of Psychology, 15, 1-17.

Baumeister, R., Heatheron, T. and Tice, D. (1994). Losing Control: How and Why People Fail at Selfregulation. San Diego, CA: Academic Press.

Bernstein, B. (1991). Central issue importance as a function of gender and ethnicity. Current Psychology, $10,241-252$.

Bowman, P. (1992). Coping with provider role strain: adaptive cultural resources among black husbandfathers. In African American Psychology: Theory, Research and Practice, Burlew, A. Banks, W. McAdoo, H. and Azibo, D. (Eds). Newbury Park: Sage Publications, pp. 135-154.

Cantor, N., Norem, J. K., Niedenthal, P., Langston, C. and Bower, A. (1987). Life tasks, self-concept ideals, and cognitive strategies in a life transition. Journal of Personality and Social Psychology, 53, $1178-1191$.

Carver, C. and Scheier, M. (1981). Attention and Self-regulation: A Control Therapy Approach to Human Behavior. Berlin, Germany: Springer-Verlag.

Cernkovich, S. and Giordano, P. (1992). School bonding, race and delinquency. Criminology, 30, 261-291.

Crane, J. (1991). Effects of neighborhoods on dropping out of school and teenage childbearing. In The Urban Underclass, Jencks, C. and Peterson, P. E. (Eds). Washington, DC: Brookings.

Csiksezentmihalyi, M. and Larson, R. (1984). Being Adolescent: Conflict and Growth in the Teenage Years. New York, NY: Basic Books.

Curry, C., Trew, K., Turner, I. and Hunter, J. (1994). The effect of life domains on girls' possible selves. Adolescence, 29, 133-150.

Damon, W. and Hart, D. (1986). Stability and change in children's self-understanding. Special issue: developmental perspectives on social-cognitive theories. Social Cognition, 4, 102-118.

Dweck, C. (1996). Social motivation: goals and social-cognitive processes. A comment. In Social Motivation: Understanding Children's School Adjustment, Juvonen, J. and Wentzel, K. (Eds). New York, NY, US: Cambridge University Press, pp. 181-195.

Dweck, C. and Leggett, E. (1988). A social-cognitive approach to motivation and personality. Psychological Review, 95, 256-272.

Elliott, E. and Dweck, C. (1988). Goals: an approach to motivation and achievement. Journal of Personality and Social Psychology, 25, 109-116.

Finn, J. D. and Rock, D. A. (1997). Academic success among students at risk for school failure. Journal of Applied Psychology, 82, 221-234.

Flaskerud, J. H. and Li-Tze, H. (1992). Relationship of ethnicity to psychiatric diagnosis. Journal of Nervous and Mental Disease, 180, 296-303.

Fleming, J. and Courtney, B. (1984). The dimensionality of self-esteem II: hierarchical facet model for revised measurement scale. Journal of Personality and Social Psychology, 46, 404-421.

Ford, D. (1992). Self-perceptions of underacheivement and support for the achievement ideology among early adolescent African-Americans. Journal of Early Adolescence, 12, 228-252.

Fordham, S. (1988). Racelessness as a strategy in Black students' school success: pragmatic strategy or pyrrhic victory? Harvard Educational Review, 58, 54-84.

Gibbs, J. T. and Hines, A. (1989). Factors related to sex differences in suicidal behavior among black youth: Implications for intervention and research. Journal of Adolescent Research, 4, 152-72.

Harter, S. (1990a). Self and identity development. In At the Threshold: The Developing Adolescent, Feldman, S. S. and Elliot, G. R. (Eds). Cambridge, MA: Harvard University Press, pp. 352-387.

Harter, S. (1990b). Developmental differences in the nature of self understanding. Cognitive Therapy and Research, 14, 113-142.

Harter, S. (1996). Teacher and classmate influences on scholastic motivation, self-esteem, and level of voice in adolescents. In Social Motivation: Understanding Children's School Adjustment, Juvonen, J. and Wentzel, K. (Eds). New York, NY, US: Cambridge University Press, pp. 11-42.

Heatherton, T. and Nichols, P. (1994). Personal accounts of successful versus failed attempts at life change. Personality and Social Psychology Bulletin, 20, 664-675.

Higgins, E. T. (1996). The self-digest: self knowledge serving self-regulatory functions. Journal of Personality and Social Psychology, 71, 1062-1083. 
Juvonen, J (1996). Self-presentation tactics promoting teacher and peer approval: the function of excuses and other clever explanations. In Social Motivation: Understanding Children's School Adjustment, Juvonen, J. and Wentzel, K. (Eds). New York, NY, US: Cambridge University Press, pp. 43-65.

Kamii, M. (1990). Opening the algebra gate: removing obstacles to success in college preparatory mathematics courses. Journal of Negro Education, 59, 392-406.

McWhorten, J. (2000). Losing the Race: Self-sabotage in Black America. New York, NY: Free Press.

Mischel, W. (1996). From good intentions to will-power. In The Psychology of Action, Gollwitzer, P. M. and Bargh, J. (Eds). New York, NY: The Guildford Press, pp. 197-218.

Morretti, M. and Higgins, E. T. (1990). Relating self-discrepancy to self-esteem: the contribution of discrepancy beyond actual-self rating. Journal of Experimental Social Psychology, 26, 108-123.

Myers, H. F., Taylor, S., Alvy, K. T., Arrington, A. and Richardson, M. A. (1992). Parental and family predictors of behavior problems in inner-city black children. American Journal of Community Psychology, 20, 557-576.

Neighbors, H., Jackson, J., Campbell, L. and Williams, D. (1989). The influences of racial factors on psychiatric diagnosis: a review and suggestions for research. Community Mental Health Journal, 25, 301-311.

Nettles, M. T. and Perna, L.W. (1997) The African American Education Databook, Vol.1: Higher and Adult Education. Frederick D. Patterson Research Institute of the College Fund/UNCF.

Otto, L. (1991). Today's youth and tomorrow's careers': a social psychological career development program. Journal of Applied Sociology, 8, 19-35.

Oyserman, D. (1993). Who influences identity: adolescent identity and delinquency in interpersonal context. Child Psychiatry and Human Development, 23(3), 203-214.

Oyserman, D., Bybee, D. and Terry, K. (2001a). Gendered Racial Identity: Possible Selves and School Involvement. Manuscript under editorial review. Ann Arbor, MI: University of Michigan.

Oyserman, D., Harrison, K. and Bybee, D. (2001b). Can racial identity be promotive of academic efficacy in adolescence? International Journal of Behavioral Development, 25(4), 379-385.

Oyserman, D., Gant, L. and Ager, J. (1995). A socially contextualized model of African American identity: school persistence and possible selves. Journal of Personality and Social Psychology, 69, 1216-1232.

Oyserman, D. and Harrison, K. (1998). Implications of ethnic identity: African American identity and possible selves. In Prejudice: The Target's Perspective, Swim, J. K. and Stangor, C. (Eds). San Diego, CA: Academic Press, pp. 281-300.

Oyserman, D. and Markus, H. (1990a). Possible selves and delinquency. Journal of Personality and Social Psychology, 59, 112-125.

Oyserman, D. and Markus, H. (1990b). Possible selves in balance: implications for delinquency. Journal of Social Issues, 46, 141-157.

Oyserman D. and Markus, H. (1993). The sociocultural self. In Psychological Perspectives on the Self, Vol. 4, Suls, J. and Greenwald, A. G. (Eds). Hillsdale, NJ: Lawrence Erlbaum, pp. 187-220.

Oyserman, D. and Saltz, E. (1993). Competence, delinquency, and attempts to attain possible selves. Journal of Personality and Social Psychology, 65, 360-374.

Petersen, A., Compas, B., Brooks-Gunn, J., Stemmler, M., Ey, S. and Grant, K. (1993). Depression in adolescence. American Psychologist, 48, 155-168.

Price, R., Cioci, M., Penner, W. and Trautlein, B. (1993). Webs of influence: school and community programs that enhance adolescent health and education. Teachers College Record, 94, 487-521.

Soloranzo, D. (1992). An exploratory analysis of the effects of race, class and gender on student and parent mobility aspirations. Journal of Negro Education, 61, 30-44.

Strauman, T. and Higgins, E. T. (1987). Automatic activation of self-discrepancies and emotional syndromes: when cognitive structures influence affect. Journal of Personality and Social Psychology, 53, 1004-1014. 